\title{
Artikkeli
}

\section{Aktiivinen yleisö?}

\section{Tutkimus yleisön asenteista sisällön tuottamista ja jakelua sekä verkossa osallistumista kohtaan}

\begin{abstract}
Verkko ja sosiaalinen media ovat muuttaneet mediasisältöjen tuotantoon, jakeluun ja kuluttamiseen liittyviä asetelmia. Näiden muutosten myötä mediayleisöä on kuvattu entistä aktiivisemmaksi. Muutoksesta kertovat tutkimukset ja tilastot keskittyvät yleisesti tarkastelemaan verkon ja sosiaalisen median käyttötapoja ja yleisön toimintaa. Tässä artikkelissa näkökulmana on yleisön asenteiden tutkimus, eli miten yleisö arvottaa omaa rooliaan aktiivisina osallistujina. Tavoitteena on tarkastella erityisesti yleisön asennoitumista sisällön tuottamista ja jakelua kohtaan verkossa. Tutkimusaineistona on laaja survey-aineisto suomalaisista verkon käyttäjistä. Analyysimenetelmänä käytetään tilastollisia menetelmiä (faktorianalyysi, summamuuttajat ja ristiintaulukoinnit). Tulosten mukaan yleisö asennoituu varauksellisesti aktiiviseen osallistumiseen ja haluaa olla näkymättömissä. Tuloksia tulkitaan artikkelissa myös sosiaalisten representaatioiden kautta. Asenteiden perusteella muotoillaan kolme mediayleisöä kuvaavaa representaatiota: perinteisen mediayleisön, aktiivisen kansalaisen ja digieläjän representaatio. Tutkimuksen päällimmäisin havainto on, että asenteellisella tasolla yleisö suhtautuu itseensä perinteisenä mediayleisönä.
\end{abstract}

AVAINSANAT: mediayleisö, käyttäjälähtöinen sisältö (user-generated content UGC), käyttäjäjakelu (user-distributed content UDC), asenne, sosiaalinen representaatio

$\mathrm{V}$ erkko ja sosiaalinen media ovat muuttaneet mediasisältöjen tuotantoon, jakeluun ja kuluttamiseen liittyviä asetelmia. Yleisön roolina ei ole olla pelkkä vastaanottaja, vaan se voi myös osallistua mediasisältöjen tuotantoon ja jakeluun. Tämä asetelman muutos on virittänyt runsaasti niin empiiristä tutkimusta kuin käsitteellistä pohdintaa yleisön roolista ja toimintatavoista. Monet tutkimukset ja tilastot keskittyvät verkon ja sosiaalisen median käyttötapoihin ja yleisön toimintaan - harvinaisempi näkökulma on yleisön asenteiden tutkimus, eli miten he arvottavat omaa rooliaan aktiivisina osallistujina. Tämän artikkelin kontribuutio media- ja yleisötutkimukseen on tarkastella nimenomaan yleisön asennoitumista sisällön tuottamista ja jakelua kohtaan. Emme siis pohdi, kuinka aktiivista yleisö sinänsä on vaan miten se 
asennoituu verkossa osallistumiseen ja uuteen, mahdollisesti aiempaa aktiivisempaan rooliinsa.

Yleisön muutosta aktiivisemmaksi toimijaksi on kuvattu monenlaisilla käsitteillä ja muutoksen merkitystä on pohdittu niin yhteiskunnalliselta kuin mediayhtiöidenkin kannalta. Empiirisesti yleisön roolin muutosta on tavallisesti tarkasteltu yleisön toimintatapojen tai verkkopalveluiden käytön tilastollisilla analyyseilla (Suomen tilanteesta esim. Tilastokeskus 2014; Newman \& Levy 2014; Matikainen \& Villi 2013). Näissä verkon ja sosiaalisen median käyttötutkimuksissa on selkeä aukko siinä, millaisena yleisö itse näkee oman roolinsa ja minkälaista muutosta on havaittavissa yleisön ajattelutavoissa ja asenteissa. Yleisötutkimuksen parissa on kuitenkin tehty paljon tutkimusta, jossa tarkastellaan yleisön merkityksenantoa ja mediasuhdetta (Heikkilä ym. 2012). Samalla on tutkittu hyvin vastaavia ilmiöitä kuin asenteet, vaikka tutkimuksissa ei olisikaan eksplisiittisesti käytetty asenteen käsitettä. Tällainen yleisötutkimus on yleensä laadullista. Näistä lähtökohdista käsillä olevan tutkimuksen voi asemoida määrällistä käyttötutkimusta ja laadullisesti orientoitunutta merkityksenantoon liittyvää tutkimusta yhdistäväksi.

Aiemmat puhtaasti asenteisiin keskittyvät tutkimukset liittyvät usein yleisön tai käyttäjien kuluttajarooliin, jolloin on tutkittu asenteita verkkosisältöjen ja -palveluiden käyttöä, maksullisuutta sekä markkinointia kohtaan (esim. Ayeh ym. 2013; Westlund 2010). Muun muassa Lim (2014) on tutkinut sosiaalisen median käyttäjien asenteita tuottamista ja jakamista kohtaan sekä asenteiden yhteyttä uutisten vastaanottoon. Keskeinen tulos Limin tutkimuksessa oli, että sosiaalisen median käyttäjien asenteet vaikuttavat verkon uutispalveluihin suhtautumiseen sekä halukkuuteen maksaa verkkosisällöistä. Yleisön suhtautumista sisällön jakeluun ja muiden jakaman sisällön kulutukseen on tutkittu (Enda \& Mitchell 2013; Glynn ym. 2011; Hermida ym. 2012; Lee \& Ma 2012) erityisesti siitä näkökulmasta, miten kulutukseen ja jakeluun vaikuttaa se, että sisältöjä kuluttavat ja jakavat tutut ihmiset.

Tämän artikkelin lähtökohtana on yleisön muuttuneesta ja aktivoituneesta roolista käytävä teoreettinen keskustelu sekä yleisön roolia kuvaavat käsitteet, keskeisimpinä näistä käyttäjätuotanto (produsage, Bruns 2007), käyttäjälähtöinen sisältö (user-generated content UGC) sekä sisällön käyttäjäjakelu (user-distributed content UDC, Villi 2011; 2012b). Teoreettismetodologisena kontekstina on asenteen käsite ja sen operationalisointi. Asenteen käsitettä laajennetaan artikkelissa sosiaalisen representaation käsitteellä, jonka tavoitteena on kytkeä asenne laajempaan sosiaaliseen ja kulttuuriseen kehykseen. Empiirisenä aineistona on laaja Suomessa tehty survey-kysely, joka antaa tilastollisesti edustavan kuvan suomalaisista verkonkäyttäjistä. Tutkimuskysymykset, aineisto, analyysi ja tulokset esitetään perinteisen tutkimusartikkelin tavoin.

\section{Yleisön uusi rooli}

Mediasisällöt ovat siirtymässä enenevissä määrin verkkoon. Verkkoympäristö tekee ongelmallisiksi selkeät rajanvedot yleisön, tuottajan ja käyttäjän välillä (Livingstone 
1999, 63) sekä kaikkiaan kyseenalaistaa koko yleisön käsitteen (Villi 2012a, 10). Vain osa verkossa median parissa vietetystä ajasta on yleisönä olemista ja kasvava osa mediasuhdetta on tekeminen: jakaminen, kommentointi, editointi ja luominen (Merrin 2009, 24). Voikin olla täsmällisempää puhua yleisön sijaan tai ohella käyttäjistä, jotka ovat internetissä enemmän tai vähemmän aktiivisesti toimivia ihmisiä (van Dijck 2009, 41).

Yleisön ja käyttäjien roolin korostumista mediasisältöjen tuotannossa ja jakelussa on kuvattu monin eri käsittein. Bruns (2007) puhuu käyttäjätuotannosta (produsage), joka korostaa yhteisöllistä tiedon tuottamista ja jalostamista. Käyttäjätuotanto perustuu arvoketju-ajatteluun, jossa perinteisesti tuottaja, jakelija ja kuluttaja ovat lineaarisessa järjestyksessä. Aineettomien, informaatioon perustuvien tuotteiden kohdalla tämä perinteinen arvoketju ei kuitenkaan välttämättä ole enää pätevä. Perinteisesti tuottaja tai jakelija on joko yksilö tai organisaatio, mutta verkossa tuotanto ja jakelu voivat tapahtua monimuotoisesti organisoituvassa yhteisössä tai parvessa.

Käyttäjälähtöinen sisältö (user-generated content UGC) on hyvin läheinen käyttäjätuotannolle. Östman (2012) esittää, että käyttäjälähtöisellä sisällöllä on kaksi peruspiirrettä. Ensinnäkin siihen kuuluu alkuperäisen sisällön tuottaminen tai olemassa olevan sisällön muokkaaminen. Toiseksi käyttäjälähtöiseen sisällöntuotantoon kuuluu sen jakaminen jollain tavalla verkossa. OECD:n (2007, 9-10) määritelmän mukaan käyttäjälähtöinen sisältö edustaa verkossa julkisesti saatavilla olevaa sisältöä, joka ilmentää ainakin jonkinasteista luovaa ponnistelua, eikä sisällön tuotantoympäristö ole ammattimainen.

Tutkimuksissa on kuitenkin tuotu esiin myös se, että useimmat yleisön jäsenet ovat varsin tyytyväisiä "vaivattomaan" asemaansa mediasisältöjen vastaanottajina (Heikkilä \& Ahva 2015) ja kuluttajina (Larsson 2011). Yleisö ei siis välttämättä ole kovin laajalti muuttunut käyttäjiksi ja tuottajiksi. Havainnoissa aktiivisesta yleisöstä voikin olla pitkälti kyse siitä, että yleisön toiminta on verkossa näkyvämpää ja dokumentoitua. Esimerkiksi yksityiset kokemukset kuten lukeminen ovat hiljalleen muuttumassa verkon myötä entistä julkisemmaksi ja sosiaalisemmaksi toiminnaksi, vaikka lukeminen ei aikaisemminkaan ole ollut täysin yksityinen kokemus (Herkman \& Vainikka 2012). Yleisöys on kiinni vahvemmin jokapäiväisissä sosiaalisissa suhteissa ja sosiaalisissa verkostoissa (Hermes 2009, 116; Heikkilä ym. 2012), nykyään eritoten median ja sosiaalisen median linkittyessä yhä tiukemmin toisiinsa (Couldry 2009, 444-445). Massayleisö on siis edelleen olemassa, mutta sen tavat kuluttaa mediaa massana ja olla yhteydessä toisiinsa ovat monipuolistuneet (Heikkilä \& Ahva 2015). Kaikkiaan kaksinapainen ja polarisoiva jako vanhan ja passiivisen sekä uuden ja aktiivisen yleisön kesken on historiallisesti katsoen liian kärjistävä (Heikkilä \& Ahva 2015; van Dijck 2009).

Aktiivisesti mediasisältöä tuottaa kuitenkin vain pieni joukko yleisöstä (esim. Matikainen \& Villi 2013; van Dijck 2009, 47; Croteau ym. 2012, 255). Huomattavasti yleisempää on mediasisällön jakaminen. Tästä toiminnasta voidaan käyttää muun muassa käsitteitä sisällön käyttäjäjakelu (user-distributed content UDC, Villi 2012b; Napoli 2009; Lietsala \& Sirkkunen 2008, 17), sosiaalinen kuratointi (Villi 2011) tai super- 
jakelu (superdistribution, Anderson ym. 2013). Nämä käsitteet kuvaavat sitä, kuinka yleisö pystyy helposti ja vaivattomasti jakamaan tutuilleen lukemiaan, katsomiaan ja kuuntelemiaan mediasisältöjä. Kyse ei siis ole pelkästään omien luomusten ja aikaansaannosten jakamisesta vaan muiden kuluttajien sekä eritoten ammattilaisten tuottamien sisältöjen uudelleenjakamisesta sosiaalisessa mediassa. Jaettava sisältö koostuu pitkälti perinteisistä joukkoviestinnän sisällöistä, mutta toiminta ei ole niinkään joukkoviestintää kuin vertaisviestintää (Livingstone 2004, 76-77; Schäfer 2011, 12-13). Voi myös ajatella, että sisältöjen jakaminen on eräänlaista "kevyt-osallistumista" tai "helppoa osallistumista" (Newman \& Levy 2013, 70; Jenkins ym. 2013, 199; Chung 2008, 673), koska esimerkiksi Facebookin suosittele-painikkeen painaminen ei vaadi samanlaista yritteliäisyyttä kuin tweetin tai päivityksen kirjoittaminen.

Yleisön rooliin sisältöjen tuottajana ja jakelijana liittyy monia odotuksia ja seurauksia, jotka voidaan jakaa kahteen tasoon: yhteiskunnallisiin sekä mediaan ja mediayhtiöihin liittyviin. Tasojaottelu perustuu Bechmannin ja Lomborgin $(2012,774)$ tapaan jäsentää yleisön tai käyttäjien tuottama kahdenlainen arvo. Käyttäjät voivat aktiivisella toiminnallaan tuottaa tulkintoja ja merkityksiä, jotka auttavat sosiaalisen todellisuuden rakentumisessa. Tämä arvo on ensisijaisesti yhteiskunnallista. Toiseksi käyttäjät voivat tuottaa mediayhtiöille rahallista arvoa.

Yhteiskunnalliset odotukset ja seuraukset liittyvät pitkälti osallistumiseen ja demokratian muutokseen. Verkkoon on toiminta- ja viestintäympäristönä liitetty suuria odotuksia demokratian rikastuttajana, mutta myös pessimististä pelkoa on havaittavissa. Empiiriset tulokset ovat ristiriitaisia, eli tukea voidaan saada niin positiivisille odotuksille kuin pessimismille (Freelon 2010). Olennaista tietysti on, millaisesta teoreettisesta näkökulmasta empiirisiä tuloksia tulkitaan. Varsin yleisenä tulkintakehyksenä on käytetty deliberatiivisen demokratian teorioita - toisaalta deliberatiivinen näkökulma jättää huomiotta verkko-osallistumisen ja -keskusteluiden tärkeitä muotoja (emt.). Keskeisenä ongelmana on pidetty sitä, että deliberatiivista näkökulmaa on sovellettu liian kapeasti keskittyen kansalaisten ja poliittisen eliitin väliseen vuorovaikutukseen ja sen kehittämiseen verkossa, vaikka internet ja erityisesti sosiaalinen media ovat omaehtoisen poliittisen ja yhteiskunnallisen organisoitumisen paikkoja (Davis 2010). Monet esimerkit osoittavat, että nimenomaan verkossa tapahtuu omaehtoista yhteiskunnallista ja poliittista aktivoitumista. Suomessa tästä on ilmeisin esimerkki maahanmuutosta käytävä keskustelu ja kinastelu. Selvää käsitystä tällaisen yhteiskunnallisen aktivoitumisen pidempiaikaisista seurauksista ei kuitenkaan vielä ole.

Median toiminnan ja mediayhtiöiden kannalta muutos yleisössä tarkoittaa puolestaan sitä, ettei yleisö ole arvokas vain kuluttajana, vaan yleisön tekemä työ - sisällön tuottaminen ja jakelu - on taloudellisen arvon tuottaja mediayhtiöille (Napoli 2009). Sosiaalisen median palveluiden liiketoimintamalli perustuu käyttäjien luomalle sisällölle ja erityisesti sen saamalle huomiolle - aktiivinen yleisö tuottaa sisältöliikennettä, jota sitten voi myydä mainostajille. Mediayhtiöiden kannalta yleisön toiminnalla saattaa siis olla taloudellista arvoa tuottava merkitys. Tämä eroaa siitä, miten perinteisessä joukkoviestinnän mallissa arvoa loi yksinään mediayhtiö. 


\section{Asenteiden tutkimus}

Asenne on yksi sosiaalipsykologian ja yleisemminkin yhteiskuntatutkimuksen peruskäsitteistä. Perinteisesti asenne on määritelty yksilön myönteiseksi tai kielteiseksi suhtautumistavaksi, joka koostuu kolmesta komponentista (Rainio \& Helkama 1974, 117): kognitiivisesta, affektiivisesta ja toiminnallisesta. Eagly ja Chaiken $(1993,1)$ puolestaan määrittelevät asenteen "psykologiseksi tendenssiksi, joka ilmaistaan, kun jotain kokonaisuutta arvioidaan myönteisesti tai kielteisesti". McGuire $(1985,239)$ luonnehtii asenteita responsseiksi, joissa kohteita asetetaan arvioinnin ulottuvuuksille. Useimpia asennemääritelmiä yhdistää kohteellisuus ja arvottavuus (Vesala \& Rantanen 1999, 10-11). Asenne suuntautuu jonkin kohteen (ilmiöt, asiat, ihmiset, organisaatiot tms.) arvottamiseen. Tavallisesti ajatellaan, että kohde on jokin konkreettinen ja helposti rajattava, mutta yhtä hyvin asenteen kohde voi olla abstrakti (McGuire 1985, 239) tai itseen liittyvää, kuten ihmisen omat vaikutusmahdollisuudet (Vesala \& Rantanen 1999). Toinen asenneteorioita yhdistävä piirre on arvottavuus. Tavallisesti kohdetta arvotetaan ulottuvuudella positiivinen-negatiivinen. Monet sosiaalipsykologit pitävät tätä evaluatiivista aspektia asenteen tärkeimpänä ominaisuutena (McGuire 1985, 239). Edellisistä määritelmistä on sekä yksiulotteisia että kolmen komponentin muodostamia määritelmiä. Asennetutkimuksessa onkin tapahtunut siirtymä yksiulotteisesta asennekäsityksestä monimuuttujaisiin asennekäsitteisiin (Huotilainen 2005, 21).

Keskeinen tutkimuksellinen ongelma on ollut asenteen ja käyttäytymisen välinen yhteys (Potter 1996). Käyttäytymistä on yritetty liittää asenteeseen monella tavalla. Tunnetuin lienee Fishbeinin ja Ajzenin (1975) malli, jossa asenne on yksi käyttäytymistä säätelevä tekijä. Jaspars ja Fraser (1984, 110-113) kuitenkin esittävät monitasoista kritiikkiä Fishbeinin ja Ajzenin mallia kohtaan, ja asenteen ja käyttäytymisen välinen suhde on jäänyt epäselväksi. Asenteen ja käyttäytymisen välistä suhdetta on yritetty selittää lisäksi monilla tavoilla, mutta tulokset eivät yleisellä tasolla ole olleet juurikaan parempia (Eagly \& Chaiken 1993). Fazio ja Zanna (1981, 197) toteavatkin, että täydellistä, eri tilanteet ylittävää yhtäpitävyyttä asenteiden ja käyttäytymisen välillä ei voida edes olettaa.

Asenneteoriaa on kritisoitu erityisen voimakkaasti individualismista (ks. esim. Potter 1996). Individualistisessa kehyksessä on pohdittu muun muassa sitä, millaisia funktioita asenteilla on yksilön psyykkisessä toiminnassa. Useimmiten on oletettu, että asenteiden tai asenteiden komponenttien tulee olla tasapainossa (Jaspars \& Fraser 1984). Myös asenteiden operationalisointiin ja mittaamiseen liittyy ongelmia (Potter 1996, 135-136). Asennemittareissa oleville käsitteille annetaan erilaisia merkityksiä, eivätkä vastaukset välttämättä asetu tutkijan asettamiin luokkiin (esimerkiksi ns. Likert-asteikolle). Tiettyihin luokkiin pakotetuista vastauksista voidaan muotoilla asenne, mutta asenteet eivät välttämättä ole yhtä yhdenmukaisia kuin asteikot.

Edellisiä asennetutkimuksen ongelmia voidaan ratkoa laventamalla asenteiden tulkintaa sosiaalisiin representaatioihin, joiden tutkimus käsitteellistää paljolti 
samoja ilmiöitä kuin asennetutkimus (Moscovici 1984). Sosiaaliset representaatiot ovat arvojen, ajatusten ja käytäntöjen järjestelmiä, joilla on kaksi funktiota: ne luovat järjestystä, jonka avulla yksilöt orientoituvat maailmaan, ja mahdollistavat kommunikaation antamalla tietyn yhteisön jäsenille koodin, jolla nimetään ja luokitellaan maailmaa, yksilöitä ja historiaa (Jaspars \& Fraser 1984, 102). Sosiaalisia representaatioita on tutkittu erityisen paljon uusiin yhteiskunnallisiin ilmiöihin liittyen (Sakki \& Menard 2014). Sosiaalisten representaatioiden tutkimus on mediatutkimuksessa hieman vieraampaa, mutta kiinnostus sitä kohtaan on viime aikoina herännyt (Höijer 2011). Sosiaalisia representaatioita on jonkin verran sovellettu uuteen teknologiaan liittyen, esimerkiksi älypuhelinriippuvuuden (Ahn \& Jung 2014) tai opettajien teknologiasuhteen (Kilpiö 2008) tutkimuksessa. Verkkoviestinnän ja uusien viestintäalustojen vaikutus yleisön osallistumiseen on sopiva tutkimuskohde sosiaalisten representaatioiden näkökulmasta.

Sosiaalisissa representaatioissa on kaksi perusmekanismia: ankkurointi ja objektivointi. Ankkurointi on mekanismi, jossa uudet asiat asetetaan tuttuun kontekstiin ja redusoidaan tavanomaisiin kategorioihin ja mielikuviin (Moscovici 1984, 29). Ankkureina voivat olla vallitsevat ajatusmallit, mielikuvat ja sosiaaliset normit (Sakki \& Menard 2014). Objektivointi puolestaan tarkoittaa abstraktin muuntamista konkreettiseksi, ja se voi tapahtua esineen, kuvan, henkilön tai metaforan kautta (emt.). Objektivointi voi johtaa naturalisoituneeseen sosiaaliseen representaatioon, joka on kyseenalaistamaton, itsestään selvä ja jopa normatiivinen. Tällöin sosiaalinen representaatio on myös vallankäytön väline.

On ehdotettu, että sosiaalisten representaatioiden tutkimus syrjäyttäisi asenteiden tutkimuksen (Jaspars \& Fraser 1984). Toisaalta taas asennetta ja sosiaalisia representaatioita on pyritty integroimaan (Potter 1996). Ideana on, että sosiaalinen representaatio luo yleisemmän merkitysjärjestelmän, jonka puitteissa kohteita arvotetaan seuraavan kaavion mukaisesti (emt. 139):

kohde $\longrightarrow$ sosiaalinen representaatio $\longrightarrow$ asenne

Sosiaalinen representaatio yhdistää kohteen ja asenteen tekemällä kohteen merkitykselliseksi ja järkeväksi, jolloin siihen voidaan asennoitua. Potterin tulkinta asenteista ja sosiaalisista representaatioista perustelee siis molempien käsitteiden käyttöä. Räty $(1987,15)$ toteaa samansuuntaisesti, että "asenne on järkevää kytkeä yhteiskunnan kulttuuriseen merkitysjärjestelmään, representaatioon". Yleisesti asenteiden ja sosiaalisten representaatioiden erona pidetään jaettuja käsityksiä ja erovaisuuksia. Asennetutkimus on etsinyt yksilöiden välisiä eroja asenteissa, kun taas sosiaalisten representaatioiden tutkimus on etsinyt yhteisesti jaettuja ilmiöitä (Huotilainen 2005, 22). Vaikka uudemmat asennetulkinnat lähenevät sosiaalisten representaatioiden teoriaa, on näiden teorioiden sosiaalisessa perustassa nähtävissä eroja: sosiaaliset representaatiot ovat perustaltaan sosiaalisia eli ryhmien luomia tulkintoja, kun taas perinteinen asennetutkimus on yksilölähtöisempää (Huotilainen 2005, 22). On kuitenkin hedelmällistä yhdistää asenteiden ja sosiaalisten representaatioiden tutkimusta, 
koska ne suuntautuvat samankaltaisiin kysymyksiin, liikkuvat teoreettisesti samalla maaperällä ja lisäksi hyödyntävät samoja tutkimusmenetelmiä.

Tässä tutkimuksessa tutkitaan asenteita melko perinteisellä menetelmällä käyttämällä määrällistä survey-aineistoa, tiedostaen kuitenkin edellä mainitut asennetutkimuksen ongelmat. Pyrkimyksenä on liittää löydetyt asennoitumistavat laajempiin sosiaalisiin representaatioihin. Sosiaalisten representaatioiden tutkimuksessa käytetään monipuolisia menetelmiä, niin laadullisia kuin määrällisiä (Huotilainen 2005). Sosiaalisten representaatioiden tutkimukselle on ominaista vahva tulkinnallisuus, jolloin yhteys empiiriseen aineistoon ei ole yhtä suoraviivainen kuin esimerkiksi asenteiden mittaamisessa.

\section{Tutkimuskysymykset}

Kolme ensimmäistä tutkimuskysymystä ovat empiirisiä ja neljäs kysymys teoreettisempi, jonka tarkoituksena on tulkita empiirisiä tuloksia. Ensimmäinen tutkimuskysymys keskittyy selvittämään asenteiden luonnetta:

1. Millaisia ovat suomalaisten verkkokäyttäjien asenteet verkossa osallistumista, sisältöjen jakamista ja tuottamista kohtaan?

Toisessa tutkimuskysymyksessä keskitytään sosio-demografisten tekijöiden tarkasteluun:

2. Miten asenteet jakautuvat iän, sukupuolen ja ammatin suhteen?

Kolmannen tutkimuskysymyksen tavoitteena on avata toiminnan ja asenteiden välistä suhdetta tarkastelemalla sisällön jakamista ja yhteisöpalveluiden käyttöä suhteessa asenteisiin:

3. Millainen on osallistumista, sisältöjen jakamista ja tuottamista koskevien asenteiden yhteys sisältöjen jakamiseen ja yhteisöpalveluiden käyttöön?

Neljännen tutkimuskysymyksen tarkoituksena on tulkita löydettyjä asenteita laajemmassa sosiaalisessa ja kulttuurisessa kehyksessä:

4. Millaisiin sosiaalisiin representaatioihin verkossa osallistumista, sisältöjen jakamista ja tuottamista koskevat asenteet kytkeytyvät?

\section{Aineiston keruu ja analyysi}

Kysely toteutettiin Taloustutkimuksen internet-paneelia hyödyntäen heinäkuussa 2012. Kyselyyn vastasi 1081 henkilöä. Tutkimuksen otanta tapahtui satunnaisesti (ohjelmallisesti) Taloustutkimuksen internet-paneelista kohderyhmärajojen puitteissa. Kyseisen paneeliin jäsenet on rekrytoitu koko väestöstä satunnaisotantaan perustuvilla menetelmillä. Kyselyaineisto on painotettu edustamaan väestöä iän, sukupuolen ja asuinalueen mukaan. Aineisto normaalius on oletettua perustuen aineiston painotukseen. Otos edustaa kohtalaisen hyvin suomalaisia verkon käyttäjiä ja tulokset voidaan yleistää suomalaisiin verkon käyttäjiin. Tulosten virhemarginaali on välillä 0,9-3,2 prosent- 
tia vastauksesta riippuen (95 prosentin luottamustasolla). Painotusta on käytetty silloin kun on käsitelty koko aineistoa, mutta jos tarkastelun kohteena on ollut vain osa vastaajista, painotusta ei ole käytetty.

Kyselyssä tarkasteltiin laajasti ja monipuolisesti verkon ja sosiaalisen median käyttöä. Kyselylomakkeessa oli kysymyksiä sosiaalisen median ja verkon käytöstä, mobiililaitteiden käytöstä, sisältöjen jakamisesta ja kierrätyksestä sekä asenneosio, jossa oli 26 asenneväittämää koskien vastaajien suhtautumista verkossa tapahtuvaan toimintaan, osallistumiseen, osallistumismotiiveihin, vuorovaikutukseen ja sisällön jakamiseen. Asenneosiossa käytettiin Likert-asteikkoa, eli asteikko oli 1-5 (1= samaa mieltä ja $5=$ eri mieltä). Näiden lisäksi kysyttiin taustatietoja (asuinpaikka, sukupuoli, ikä, ammatti, koulutus ja elämänvaihe). Kyselylomake rakennettiin tutkimushankkeen tavoitteiden pohjalta, hyödyntäen aiempia kyselyitä ja tutkimustuloksia. Kyselylomake on nähtävillä verkossa'.

Vastaajista naisia oli 540 (50 \%) ja miehiä 541 (50 \%). Ikäjakauma käy ilmi taulukosta 1.

Taulukko 1. Vastaajien ikäjakauma.

\begin{tabular}{|l|l|}
\hline $15-24$ vuotta & $20 \%$ \\
\hline $25-34$ vuotta & $10 \%$ \\
\hline $35-44$ vuotta & $11 \%$ \\
\hline $45-54$ vuotta & $18 \%$ \\
\hline $55-64$ vuotta & $19 \%$ \\
\hline $65-79$ vuotta & $22 \%$ \\
\hline
\end{tabular}

Asenneväittäminen analyysi lähti liikkeelle faktorianalyysilla, jolla haettiin useaan muuttujaan perustuvia asennoitumistapoja. Löydetyistä faktoreista tehtiin summamuuttujia. Tämän jälkeen analyysiä jatkettiin summamuuttujien ja muiden muuttujien välisillä ristiintaulukoinneilla. Ristiintaulukointien kohdalla tarkasteltiin myös riippuvuuden tilastollista merkitsevyyttä (khii-toiseen-testi). Taulukoissa ja kuvioissa prosentit on pyöristetty kokonaislukuihin. Käytännössä tämä tarkoittaa sitä, että joissain taulukoissa prosentti on nolla, vaikka se todellisuudessa saattaa olla o,1:n ja o,4:n välillä. Käytännössä tällä ei kuitenkaan ole suurta merkitystä. Keskiarvot on esitetty yhden desimaalin tarkkuudella.

\section{Tulokset}

Ensimmäiseen tutkimuskysymykseen vastaamiseksi analysoimme asenneväittämiä faktorianalyysilla ${ }^{2}$, jolla tavoiteltiin laajempia asenneryhmiä verkossa ja sosiaalisessa mediassa toimimisen suhteen. Analyysin tuloksena syntyivät seuraavat kuusi asenneryhmää (kunkin alla on väittämät ${ }^{3}$ ja faktoripisteet, jonka pohjalta asenneryhmä muodostui): 
1 Sosiaalinen jakaminen (ominaisarvo 7,0, selitysosuus 26,7 \%)

- Haluan tuottaa sisältöä verkkoon, jos siitä on muille hyötyä tai iloa $(0,83)$

- Palaute ja muiden kehut lisäävät intoa sisällön tuottamiseen $(0,82)$

- Vastavuoroisuus on tärkeää: jos annan jotain verkkoon, niin myös saan sieltä jotain $(0,77)$

2 Halu vaikuttaa

- Mitä enemmän saan tuotoksilleni verkossa lukijoita tai katselijoita, sen parempi $(0,75)$

- Haluan verkossa vaikuttaa toisiin ihmisiin ja muuttaa maailmaa $(0,72)$

- Haluan jakaa sisältöä muille verkon käyttäjille $(0,63)$

3 Halu oppia

- Uusiin ihmisiin ja yhteisöihin tutustuminen innostaa osallistumaan verkossa $(0,72)$

- Tuottamalla sisältöä verkkoon voin hyödyntää sellaisia tietoja, taitoja tai kykyjä, joita en muuten käyttäisi $(0,65)$

- Opin verkossa uusia asioita $(0,63)$

- Internetissä syntyy uusia ilmiöitä, ja haluan olla niissä mukana $(0,54)$

4 Halu osallistua median toimintaan ja julkisuuden tavoittelu (ominaisarvo 4,7 , selitysosuus $18,2 \%$ )

- Lähetän mielelläni kännykälläni tuottamiani sisältöjä mediayhtiöille $(0,86)$

- Haluan tulla kuuluisaksi verkossa $(0,72)$

- Jos saan otettua hyvän uutiskuvan, lähetän sen mediaan käytettäväksi $(0,67)$

- Haluan valokuvilleni verkossa mahdollisimman laajan yleisön $(0,66)$

- Tuotan mielelläni sisältöä mediayhtiöiden käyttöön $(0,65)$

- Osallistun mielelläni keskusteluihin lehtien ja muun median keskustelualueilla $(0,64)$

5 Yhteisöpalveluissa eläminen (ominaisarvo 2,9, selitysosuus 11,2 \%)

- Yhteisöpalvelut ovat parasta verkossa $(0,78)$

- Luen uutiset mieluiten ensimmäisenä Facebookista $(0,64)$

- Haluan kertoa elämästäni verkossa $(0,62)$

- Haluan, että muut tietävät olemassaolostani verkossa $(0,54)$

6 Näkymätön oleminen (ominaisarvo 1,9, selitysosuus 7,2 \%)

- Olen mieluiten näkymättömissä verkossa ja sosiaalisessa mediassa $(0,83)$

- Haluan verkossa lähinnä vain kuluttaa toisten tuottamaa sisältöä $(0,80)$

Summamuuttujista laskettiin keskiarvot (taulukko 2). Keskiarvot osoittavat, että vastaajat ovat eniten samaa mieltä näkymätön oleminen -summamuuttujan kanssa. Tästä päättelimme, että näkymätön oleminen on vastaajille tärkeintä. Tämän jälkeen tärkeimpiä ovat sosiaalinen jakaminen sekä halu oppia ja vaikuttaa. Selvästi vähiten 
tärkeintä on mediaan osallistuminen sekä yhteisöpalveluissa esilläolo. Kaksi suurinta arvoa saaneet muuttujat, näkymätön oleminen ja sosiaalisuus, ovat pitkälti toisilleen vastakkaisia. Yllä esitetyt keskiarvot sulkevat sisälleen kaikki vastaajat, vaikka eri vastaajaryhmien kesken voisi olettaa olevan vaihtelua. Tämän vuoksi asenteita on tarkasteltava suhteessa taustamuuttujiin.

Taulukko 2. Asennemuuttujien keskiarvot (asteikko 1-5, jossa 1=eri mieltä ja 5=samaa mieltä).

\begin{tabular}{|l|l|}
\hline summamuuttuja & keskiarvo \\
\hline näkymätön oleminen & 2,9 \\
\hline sosiaalinen jakaminen & 2,7 \\
\hline halu oppia & 2,5 \\
\hline halu vaikuttaa & 2,3 \\
\hline yhteisöpalveluissa eläminen & 1,8 \\
\hline halu osallistua mediaan & 1,6 \\
\hline
\end{tabular}

Toinen tutkimuskysymyksemme kohdistuu asenteiden jakautumiseen iän, sukupuolen ja ammatin suhteen. Sukupuolten välillä asenteissa on varsin vähäisiä eroja (taulukko 3). Miehillä on hieman myönteisempi suhtautuminen mediaan osallistumiseen, kun taas naisille yhteisöpalveluissa eläminen on tärkeämpää. Näkymätön oleminen on miehille jonkin verran tärkeämpää. Muissa muuttujissa sukupuolten kesken eroja ei juuri ole. Sukupuolten kesken havaitut erot ovat melko vähäisiä, mutta erot ovat kuitenkin tilastollisesti merkitseviä (khiin neliö -testin p-arvo o,००o).

Taulukko 3. Asennemuuttujien keskiarvojen jakautuminen sukupuolten kesken.

\begin{tabular}{|l|l|l|}
\hline summamuuttuja & keskiarvo mies & keskiarvo nainen \\
\hline näkymätön oleminen & 3,0 & 2,9 \\
\hline sosiaalinen jakaminen & 2,7 & 2,8 \\
\hline halu oppia & 2,5 & 2,6 \\
\hline halu vaikuttaa & 2,4 & 2,3 \\
\hline yhteisöpalveluissa eläminen & 1,8 & 1,9 \\
\hline halu osallistua mediaan & 1,5 & 1,7 \\
\hline
\end{tabular}

Taulukossa 4 on asennemuuttujia eritelty iän mukaisesti. Halu osallistua mediaan on vähiten tärkeintä kaikissa ikäryhmissä. Näkymätön oleminen on puolestaan tärkeää kaikissa muissa ikäryhmissä paitsi nuorissa. Taulukosta havaitaan, että kaikki muut kategoriat paitsi näkymätön oleminen laskevat iän myötä melko samalla tavalla. Huomattavaa on, että nuorille sosiaalisuus sisällön tuottamisen ja jakamisen kautta on kaikkein tärkeintä, mutta sen merkitys laskee 35 ikävuoden jälkeen melko jyrkästi. 
Toisaalta nuorilla on myös vahvana asenne ja halu olla näkymättömissä. Iän suhteen erot ovat tilastollisesti merkitseviä kaikkien faktoreiden kohdalla jokaisessa ikäluokassa (khiin neliö -testin p-arvo o,ooo).

Taulukko 4. Asennemuuttujien keskiarvojen jakautuminen ikäluokittain (asteikko 1-5).

\begin{tabular}{|l|l|l|l|l|l|l|}
\hline & $\begin{array}{l}\text { näkymätön } \\
\text { oleminen }\end{array}$ & $\begin{array}{l}\text { sosiaalinen } \\
\text { jakaminen }\end{array}$ & $\begin{array}{l}\text { halu } \\
\text { oppia }\end{array}$ & $\begin{array}{l}\text { halu } \\
\text { vaikuttaa }\end{array}$ & $\begin{array}{l}\text { yhteisöpalveluissa } \\
\text { eläminen }\end{array}$ & $\begin{array}{l}\text { halu osallistua } \\
\text { mediaan }\end{array}$ \\
\hline $15-24$ & 3,1 & 3,3 & 2,9 & 2,9 & 2,2 & 1,8 \\
\hline $25-34$ & 3,1 & 2,9 & 2,9 & 2,6 & 2,0 & 1,6 \\
\hline $35-44$ & 2,9 & 2,7 & 2,5 & 2,3 & 1,8 & 1,6 \\
\hline $45-54$ & 3,0 & 2,6 & 2,5 & 2,2 & 1,7 & 1,6 \\
\hline $55-64$ & 2,8 & 2,2 & 2,1 & 1,9 & 1,5 & 1,5 \\
\hline $65-79$ & 2,6 & 2,3 & 2,2 & 1,9 & 1,6 & 1,6 \\
\hline
\end{tabular}

Ammatin suhteen asenteissa on havaittavissa selkeitä eroja (taulukko 5). Ammattiryhmistä koululaiset ja opiskelijat ovat innokkaita osallistumaan ja jakamaan sisältöä verkossa, ja he myös haluavat näkyä yhteisöpalveluissa ja vaikuttaa. Muissa ryhmissä nämä motiivit ja asenteet ovat vähäisempiä ja näkymätön oleminen on tärkeintä. Poikkeuksen muodostavat kuitenkin kotiäidit ja -isät, joille sosiaalisuus ja halu vaikuttaa ovat kaikkein tärkeintä. Eri ammattiryhmien väliset erot ovat tilastollisesti merkitseviä (khiin neliö -testin p-arvo o,000).

Taulukko 5. Asennemuuttujien keskiarvojen jakautuminen ammattiryhmittäin (asteikko 1-5).

\begin{tabular}{|l|l|l|l|l|l|l|}
\hline & $\begin{array}{l}\text { näkymätön } \\
\text { oleminen }\end{array}$ & $\begin{array}{l}\text { sosiaalinen } \\
\text { jakaminen }\end{array}$ & $\begin{array}{l}\text { halu } \\
\text { oppia }\end{array}$ & $\begin{array}{l}\text { halu } \\
\text { vaikuttaa }\end{array}$ & $\begin{array}{l}\text { yhteisö- } \\
\text { palveluissa } \\
\text { eläminen }\end{array}$ & $\begin{array}{l}\text { halu } \\
\text { osallistua } \\
\text { mediaan }\end{array}$ \\
\hline koululainen & 2,4 & 3,4 & 3,1 & 3,2 & 3,0 & 2,1 \\
\hline opiskelija & 3,1 & 3,5 & 3,0 & 2,9 & 2,2 & 1,7 \\
\hline työntekijä & 3,0 & 2,7 & 2,5 & 2,3 & 1,9 & 1,7 \\
\hline yrittäjä & 2,8 & 2,5 & 2,3 & 2,0 & 1,5 & 1,5 \\
\hline $\begin{array}{l}\text { alempi } \\
\text { toimihenkilö }\end{array}$ & 3,3 & 2,7 & 2,5 & 2,3 & 1,7 & 1,6 \\
\hline $\begin{array}{l}\text { ylempi } \\
\text { toimihenkilö }\end{array}$ & 2,9 & 2,7 & 2,5 & 2,2 & 1,6 & 1,4 \\
\hline johtava asema & 2,5 & 2,3 & 2,1 & 2,2 & 1,8 & 1,6 \\
\hline työtön & 3,0 & 2,7 & 2,6 & 2,6 & 1,9 & 1,8 \\
\hline kotiäiti tai -isä & 2,9 & 3,3 & 2,9 & 2,9 & 2,1 & 1,4 \\
\hline eläkeläinen & 2,7 & 2,4 & 2,3 & 2,3 & 1,6 & 1,6 \\
\hline muu & 2,2 & 2,8 & 2,4 & 2,2 & 2,2 & 1,6 \\
\hline
\end{tabular}


Kolmannessa tutkimuskysymyksessä tarkastelemme asenteiden suhdetta sisältöjen jakamiseen ja yhteisöpalveluiden käyttöön ${ }^{4}$. Tavoitteena on siis etsiä asenteen ja käyttäytymisen välistä yhteyttä, joskin melko yksinkertaisella tavalla. Taulukossa 6 esitetään ristiintaulukoinnin pohjalta se, miten yhteisöpalveluiden käyttö esiintyy suhteessa "yhteisöpalveluissa eläminen" -asenteeseen. Yhteisöpalvelun käyttäjät suhtautuvat myönteisemmin yhteisöpalveluissa elämiseen kuin ne, jotka eivät käytä yhteisöpalveluita. Taulukosta on pääteltävissä, että "yhteisöpalveluissa eläminen" asenteella on yhteys myös todelliseen käyttöön.

Taulukko 6. Yhteisöpalveluiden käyttö suhteessa "yhteisöpalveluissa eläminen" -asenteen kanssa (\%) (khiin neliö -testin p-arvo o,000).

\begin{tabular}{|l|l|l|}
\hline & käyttää yhteisöpalveluita & ei käytä yhteisöpalveluita \\
\hline eri mieltä & 65 & 85 \\
\hline ei samaa, eikä eri mieltä & 30 & 15 \\
\hline samaa mieltä & 5 & 0 \\
\hline yht. & 100 & 100 \\
\hline
\end{tabular}

Vastaava ilmiö tulee esille sisällön jakamisen kohdalla (taulukko 7). Sisältöjen jakaminen on voimakkaampaa niiden keskuudessa, joilla on myös myönteinen asenne sitä kohtaan. Erot ovat tilastollisesti merkitseviä. Silti taulukon perusteella ei vielä voida vetää kovin selkeää yhteyttä, vaan se vaatisi syvällisempää analyysia.

Taulukko 7. Sisällön jakaminen suhteessa "sosiaalinen jakaminen" -asenteeseen (\%) (khiin neliö -testin p-arvo o,000).

\begin{tabular}{|l|l|l|}
\hline & jakaa verkkosisältöjä & ei jaa verkkosisältöjä \\
\hline eri mieltä & 17 & 52 \\
\hline ei samaa, eikä eri mieltä & 38 & 38 \\
\hline samaa mieltä & 45 & 10 \\
\hline yht. & 100 & 100 \\
\hline
\end{tabular}

Ristiintaulukoinnit osoittavat, että asenteen ja toiminnan välillä on yhteys, mutta tuloksia voidaan pitää vasta suuntaa antavina: myönteinen asenne verkossa elämistä ja sisältöjen jakamista kohtaan on yhteydessä myös varsinaiseen toimintaan. Vaikka asenteen ja toiminnan yhteys voidaan todeta vasta yleisellä tasolla, tekee yhteyden osoittaminen asenteiden tutkimuksesta perusteltua. Asenteet näyttäytyvät merkityksellisinä tekijöinä arvioitaessa yleisön suhtautumista ja toimintaa verkkoympäristöissä. 


\section{Uuden yleisön sosiaaliset representaatiot}

Neljäs tutkimuskysymys liittyy löydettyjen asenteiden tulkintaan. Tavoitteena on liittää asenteet yleisempään sosiaaliseen ja kulttuuriseen viitekehykseen, jollaisena tässä tutkimuksena sovelletaan sosiaalisten representaatioiden tutkimusta. Tutkimuksemme kannalta on erityisen hyödyllistä se, miten sosiaalisten representaatioiden tutkimuksessa on eritelty uuden ilmiön ankkuroitumistapoja, eli niin sanottuja ankkureita (Sakki \& Menard 2014). Tässä tutkimuksessa pohdimme sitä, millaisiin representaatioihin yleisön osallistumista ja mediasisältöjen jakamista koskevat asenteet ankkuroituvat. Olemme muotoilleet asenteiden analyysin pohjalta sekä hyödyntämällä aiempia tutkimuksia kolme asenteiden ankkuroinnin perustana olevaa representaatiota.

Perinteisen mediayleisön representaatio on aineistossa kaikkein vahvin, ja se ilmenee lähinnä "näkymätön oleminen" -asenteen kautta. Myös heikko "mediaan osallistuminen" -asenne kertoo siitä, miten vastaajat tyytyvät perinteiseen mediayleisön rooliin (Carpentier 2009), eli he eivät halua aktiivisesti osallistua median toimintaan tuottamalla sisältöä tai keskustelemalla julkaisuiden verkkosivuilla tai muuten kommentoimalla. Schäfer (2011) jakaa käyttäjien osallistumisen verkossa eksplisiittiseen ja implisiittiseen muotoon. Eksplisiittisessä osallistumisessa käyttäjät tuottavat tietoisesti mediatekstejä ja muita kulttuurisia sisältöjä, kuten kirjoittavat blogia tai lisäävät tekstiä Wikipedia-artikkeliin. Implisiittisessä osallistumisessa he puolestaan vain "käyttävät" verkon palveluita, sovelluksia ja alustoja (Villi 2014). Implisiittinen osallistuminen kuvaa hyvin perinteisen mediayleisön representaatiota.

Aktiivisen kansalaisen representaatio nousee esille oppimisen ja vaikuttamisen halun muodossa. Nämä ovat perinteisiä aktiivisen kansalaisen piirteitä, joista esimerkkeinä muissa yhteyksissä ovat osallistuminen koulutukseen ja toiminta yhdistyksissä ja politiikassa. Toiminta sosiaalisessa mediassa näyttäytyy käyttäjille tämän representaation sisällä mielekkäänä (vrt. Mørk Petersen 2008), eikä sen mielekkyyttä vähennä se, että sosiaalisen median ja mediateollisuuden yritykset pystyvät käyttämään sitä hyväksi. Käyttäjät nauttivat tekemästään työstä esimerkiksi kirjoittaessaan Facebook-päivityksiä (Ritzer \& Jurgenson 2010, 21-22, 25), vaikka samaan aikaan Facebook takoo voittoa myydessään näiden kirjoitusten lomaan kohdennettuja mainoksia. Aktiivisen kansalainen representaatio on siis perinteinen, mutta toimintakonteksti näyttää olevan verkossa entiseen verrattuna kovin erilainen, esimerkiksi kaupallisuuden suhteen.

Digieläjän representaatio tulee esille erityisesti "sosiaalinen jakaminen" -asenteen myötä. Myös nuorten painotus "yhteisöpalveluissa eläminen" -asenteeseen kertoo tästä representaatiosta. Representaatiossa nykyinen mediayleisö nähdään ketteränä verkkotoimijana, joka haluaa jakaa sisältöjä ja jolle verkko ylipäätään on toiminnallinen tila (vrt. Väliverronen 2009; Malmelin \& Villi 2015). Facebook ja muut sosiaalisen median yhtiöt tarjoavat rakenteen ja alustan yleisön keskinäiselle viestinnälle. Juuri mitään sosiaalisen median palvelua ei olisikaan olemassa ilman käyttäjää joko sisällön tai sosiaalisten suhteiden tuottajana. Myös media-ala käy läpi osittaista muutosta sisällöntuottajasta palveluiden tuottajaksi tarjotessaan alustoja ja välineitä käyttäjien vuorovaikutukselle ja heidän digitaaliselle elämälleen. Joukkoviestintä sisältää yhä 
enemmän mediavälitteisen keskinäisviestinnän elementtejä. Digieläjän representaation sisällä yleisöstä voisikin puhua verkostoina (Deuze 2009, 152) tai yleisöyhteisöinä (Villi 2011, 61; Matikainen \& Villi 2015).

On tärkeää huomata, että nämä kolme representaatiota eivät painotuksista huolimatta jakaudu selkeästi eri vastaajaryhmien kesken, vaan kukin representaatio nousee esille kaikkien vastaajien joukossa. Erityisen vahvasti mediayleisö verkossa representoituu perinteiseksi mediayleisöksi. Toisaalta siinä on aineksia myös perinteisestä aktiivisesta kansalaisuudesta ja kokonaan uudesta digieläjän representaatiosta. Tässä kuvastuu representaation idea, eli keino ottaa haltuun uusi ilmiö. Erilaisten representaatioiden olemassaolo tarkoittaa sitä, että mediayleisö representoituu ja ankkuroituu tilanteesta, tulkintavasta ja sosiaalisesta ryhmästä riippuen eri tavoin.

\section{Johtopäätökset ja jatkotutkimuksen aiheet}

Tutkimuksemme päällimmäisin havainto on, että asenteellisella tasolla yleisö suhtautuu itseensä perinteisenä mediayleisönä. Yleisön asennoituminen mediassa osallistumista kohtaan ei ole välttämättä muuttunut yhtä paljon kuin monet niistä tutkijoista antavat olettaa, joiden esittämät näkemykset perustuvat usein käyttökyselyihin tai journalistien ja muiden mediassa työskentelevien haastatteluihin. Tutkimuksemme valossa näyttäisi siis siltä, että yleisön aktivoitumiseen, sisältöjen tuottamiseen (UGC) ja jakamiseen (UDC) liittyvät representaatiot ovat naturalisoituneet laajalti tutkijoiden ja media-alan edustajien parissa, mutta eivät niinkään yleisön parissa, sillä se asemoituu omista lähtökohdistaan pitkälti edelleen passiivisen mediayleisön representaatioon.

On tietysti arveluttavaa puhua yleisöstä yksikössä, sillä mediayleisö ei ole yksi yhtenäinen kokonaisuus. Internetin myötä yleisö on entistä pirstaloituneempi, ja perinteiset mediayhtiöt ovat menettäneet yleisöään verkossa oleville palveluille ja alustoille. Tässä tutkimuksessa on yleisöä empiirisellä tasolla eritelty iän, sukupuolen ja ammatin mukaisesti, mutta sensitiivisempi jaottelu olisi tarpeellinen jatkotutkimuksessa. Jaottelua on tuskin aiheellista tehdä pelkkien perinteisten taustamuuttujien mukaisesti, vaan erilaiset arvostuksiin ja elämäntapoihin liittyvät jaottelut voisivat avata kiinnostavia jäsennyksiä yleisön moninaisuudesta.

Mediayleisön muutos esitetään usein turhan kärjistävänä (van Dijck 2009). Yleisötutkimuksessa tämä on tarkoittanut osallistumista (participation) korostavan paradigman nousua (Livingstone 2013). Tässä tutkimuksessa esille nousseet asenteet ja representaatiot osoittavat, että kärjistävä kaksinapaisuus vanhan passiivisen ja uuden aktiivisen yleisön kesken on ongelmallinen. Nykyisen yleisön tapa merkityksellistää ja ankkuroida olemistaan yleisönä pitää sisällään aineksia niin "vanhasta" kuin "uudesta" yleisöstä. Jatkotutkimuksissa olisi tärkeää eritellä näitä merkityksellistämistapoja perusteellisemmin. Tämä voisi myös avata uusia näkökulmia nykyiseen mediayleisöön ja verkkokäyttäjiin, joiden toimintaa tarkastellaan usein käyttömääriä kuvaavien prosenttijakaumien kautta.

Asenteiden ja käyttäytymisen välinen suhde on ollut asennetutkimuksen perusongelma. Jossain tutkimuksissa niiden välille on osoitettu yhteys (esim. Lim 2014), mutta 
tämän tutkimuksen yhteydessä asennoitumistapojen perinteisyys suhteessa median käyttöön herättää kysymyksiä asenteen ja käyttäytymisen välisestä suhteesta. Tosin analyysimme osoitti, että aktiivisesti yhteisöpalveluissa toimivat tai sisältöjä jakavat asennoituvat myös muita myönteisemmin yhteisöpalveluissa elämiseen ja jakamiseen. Monissa aiemmissa tutkimuksissa on todettu, että yleisön toiminta on verkossa aktiivisempaa verrattuna verkkoaikakautta edeltäneeseen mediayleisöön (Potts ym. 2008, 472; van Dijck 2009, 46). Tai ainakin aktiivisuus on tullut verkon myötä näkyvämmäksi (Andrejevic 2008, 40; Cohen 2008, 7), sillä yleisön toiminta on hyvin dokumentoitavissa heidän jättämiensä digitaalisten jälkien vuoksi. Voitaneen perustellusti todeta, että asenteen ja toiminnan välinen empiirisesti melko yksinkertaisesti osoitettu yhteys ylipäätään perustelee asenteiden tarkastelemista yleisötutkimuksessa.

Asennetutkimuksen keskeisenä piirteenä ja myös ongelmana on todettu asenteiden yksiulotteinen mittaaminen. Pyrimme tutkimuksessamme ylittämään yksittäisten asenteiden tutkimuksen ryhmittelemällä asenteet faktorianalyysin avulla. Lisäksi laajensimme asenteiden tulkintaa sosiaalisten representaatioiden avulla. Representaatio tarjoaa asennetta väljemmän käsitteen yleisötutkimukseen. Representaatioiden huonona puolena voidaan kuitenkin tutkimuksemme yhteydessä pitää muodostettujen kolmen representaation epämääräistä tai väljää empiiristä perustaa. Sosiaalisten representaatioiden tutkimuksessa on hyvin kirjava keinojen joukko sosiaalisten representaatioiden muotoiluun ja tulkintaan, joten representaatioiden muodostaminen vaatisi useita empiirisiä aineistoja (Huotilainen 2005).

Mediayleisöstä puhuttaessa nousee esille kysymys sukupolvista: onko kyseessä pikemmin kyse eri sukupolvista kuin yleisön yleisemmästä muutoksesta? Tämäkin tutkimus osoittaa, että nuorten asennoitumistavoissa on eroja vanhempiin ihmisiin nähden. Yleisesti väitetäänkin, että digitaalisen verkkoteknologian myötä on syntynyt kokonaan uusi mediasukupolvi (Westlund \& Bjur 2014). Toisaalta erilaisia sukupolvitutkimuksia on kritisoitu siitä, että ne yksinkertaistavat näkemyksiä nykynuorisosta homogeenisenä digisukupolvena (Miegel \& Olsson 2012, 487). Sukupolvien väliset erot kiteytyvät verkkopalveluiden ja välineiden käyttöön, mikä voi olla liian välinekeskeinen ja teknologista determinismiä korostava ajattelutapa (emt.). Tällöin jää huomiotta sukupolvikokemus, eli sukupolven ajattelu- ja kokemusmaailmaa yhdistävät tekijät. Nuorten erilaisesta tavasta asennoitua verkkoa kohtaan ja tavasta käyttää verkkoa ei vielä voida suoraan vetää johtopäätöksiä uusista sukupolvista, vaan asiaa pitäisi tutkia laajemmin nimenomaan sukupolvikokemuksen kautta.

Asenteita tutkittaessa nousee esille myös asenteiden muutos. Tämä tutkimus ei mahdollista muutoksen tarkastelua, mutta on kuitenkin syytä pohtia asenteiden pysyvyyttä ja muutosta. Esimerkiksi inmisten tietoisuuden kasvu saattaa muuttaa asennoitumista verkko-osallistumista kohtaan. Muun muassa Edward Snowdenin paljastukset tietojen urkinnasta ja keräämisestä ovat saattaneet vaikuttaa sisällön tuotantoon ja jakamiseen liittyviin asenteisiin. Siten mediayleisön ymmärtämiseksi olisi asenteista tarpeen tehdä myös pitkittäistutkimuksia.

Asennetutkimuksella on myös käytännöllisiä ulottuvuuksia (vrt. Lim 2014). Mediayhtiöt ovat viime vuosina pyrkineet eri tavoin osallistamaan yleisöjä, mikä korostaa 
tässä tutkimuksessa esille tulleiden asennoitumistapojen merkitystä sen suhteen, miten ja millä tasolla yleisöä kannattaa osallistaa. Pyritäänkö yleisöä esimerkiksi saamaan tuottamaan sisältöä median käyttöön, kommentoimaan uutisia vai ainoastaan osallistumaan kevyemmin jakamalla verkossa julkaistuja mediasisältöjä? Yleisesti yleisö on joko pidetty erillään varsinaisesta journalistisesta toiminnasta tai sitten yleisön ohjaaminen verkossa on ollut kohtalaisen säänneltyä (Domingo 2011, 86). Syitä osallistumattomuuteen voi siten olla sekä yleisön asenteissa että mediayhtiöiden osallistamistavoissa.

\section{Viitteet}

1 http://blogs.helsinki.fi/crc-centre/files/2013/12/Mobiilit_mediasisallot_web.pdf

2 Alunperin muodostui neljä faktoria, joiden selitysosuus on 63,3\%. Ensimmäisessä faktorissa oli monta muuttujaa, joita oli sisällöllisesti vaikea yhdistää, joten ensimmäisestä faktorista muodostettiin kolme erillistä muuttujaa (sosiaalinen jakaminen, halu vaikuttaa ja halu oppia). Tämän vuoksi kolmen ensimmäisen faktorin ominaisarvo ja selitysosuus ovat vain ensimmäisessä faktorissa. Ratkaisu ei ole ihanteellinen, mutta muuttujat korreloivat keskenään, jolloin jako on paitsi sisällöllisesti myös tilastollisesti perusteltu.

3 Analyysin ulkopuolelle jäivät seuraavat väittämät: verkkoon tuottamisessa on tärkeää itsenäisyys: voin päättää mitä ja mihin tuotan, käytän internetiä mieluummin kännykällä kuin tietokoneella, tuotan sisältöä verkkoon, mutta en halua että kaikki näkevät sen, verkossa julkaisemani valokuvat on suunnattu enimmäkseen ystävilleni

4 Yhteisöpalvelun käyttöä kysyttiin väitteellä "kirjoitan tilapäivityksiä, kommentoin tai osallistun muuten yhteisöpalveluissa (esim. Facebook)". Vastausvaihtoehdot olivat useita kertoja päivässä, päivittäin, viikoittain, muutaman kerran kuukaudessa ja en lainkaan.

\section{Kirjallisuus}

Ahn, Juyeon \& Jung, Yoonhyuk (2014). The common sense of dependence on smartphone: A comparison between digital natives and digital immigrants. New Media Q Society. DOI: 10.1177/1461444814554902.

Anderson, C. W.; Bell, Emily \& Shirky, Clay (2013). Post-Industrial Journalism: Adapting to the Present. Columbia Journalism School, Tow Center for Digital Journalism. Saatavilla: http://towcenter.org/wp-content/ uploads/2012/11/TOWCenter-Post_Industrial_Journalism.pdf (luettu 16.4.2013).

Andrejevic, Mark (2008). Watching television without pity: The productivity of online fans. Television Q New Media 9: 1, 24-46.

Ayeh, Julian K.; Au, Norman \& Law, Rob (2013). Do we believe in Tripadvisor? Examining credibility perceptions and online travelers' attitude toward using user-generated content. Journal of Travel Research 52: 4, 437-452.

Bechmann, Anja (2012). Towards cross-platform value creation. Information, Communication Q Society 15: 6, 888-908.

Bruns, Axel (2007). Produsage: Towards a Broader Framework for User-Led Content Creation. C \& C '07, 13.7.6.2007, Washington, DC, USA.

Carpentier, Nico (2009). Participation is not enough: The conditions of possibility of mediated participatory practices. European Journal of Communication 24: 4, 407-420.

Chung, Deborah S. (2008). Interactive features of online newspapers: Identifying patterns and predicting use of engaged readers. Journal of Computer-Mediated Communication 13: 3, 658-679.

Cohen, Nicole S. (2008). The valorization of surveillance: Towards a political economy of Facebook. Democratic Communiqué 22: 1, 5-22.

Couldry, Nick (2009). Does "the media" have a future? European Journal of Communication 24: 4, 437-449.

Croteau, David; Hoynes, William \& Milan, Stefania (2012). Media Society: Industries, Images, and Audiences. Thousand Oaks, CA: Sage. 
Davis, Aaron (2010). New media and fat democracy: The paradox of online participation. New Media Q Society 12: 5, 745-761.

Deuze, Mark (2009). Convergence culture and media work. Teoksessa: Holt, Jennifer \& Perren, Alisa (toim.). Media Industries: History, Theory, and Method. Chichester, UK: Wiley-Blackwell, 144-156.

van Dijck, José (2009). Users like you? Theorizing agency in user-generated content. Media, Culture Q Society 31: 1, 41-58.

Domingo, David (2011). Managing audience participation: Practices, workflows and strategies. Teoksessa: Singer, Jane B.; Domingo, David; Hermida, Alfred; Heinonen, Ari; Paulussen, Steve; Quandt, Thorsten; Reich, Zvi \& Vujnovic, Marina (toim.). Participatory Journalism: Guarding Open Gates at Online Newspapers. Chichester, UK: Wiley-Blackwell, 76-95.

Eagly, Alice H. \& Chaiken, Shelly (1993). The Psychology of Attitudes. Fort Worth: Harcourt Brace College Publishers.

Enda, Jodi \& Mitchell, Amy (2013). Friends and Family - Important Drivers of News. The State of the News Media 2013. The Pew Research Center's Project for Excellence in News Journalism, an Annual Report on American Journalism.

Fazio, Russell H. \& Zanna, Mark P. (1981). Direct experience and attitude-behavior consistency. Teoksessa: Berkowitz, Leonard (toim.). Advances in Experimental Social Psychology. New York: Academic Press.

Fishbein, Martin \& Ajzen, Icek (1975). Belief, Attitude, Intention and Behaviour: An Introduction to Theory and Research. Reading, MA: Addison-Wesley.

Freelon, Deen G. (2010). Analyzing online political discussion using three models of democratic communication. New Media Q Society 12: 7, 1172-190.

Glynn, Carrol J.; Huge, Michael E. \& Hoffman, Lindsay H. (2011). All the news that's fit to post: A profile of news use on social networking sites. Computers in Human Behavior 28: 1, 113-119.

Herkman, Juha \& Vainikka, Eliisa (2012). Lukemisen tavat. Lukeminen sosiaalisen median aikakaudella. Tampere University Press.

Heikkilä, Heikkilä \& Ahva, Laura (2015). The relevance of journalism: Studying news audiences in a digital era. Journalism Practice 9: 1, 50-64.

Heikkilä, Heikki; Ahva, Laura; Siljamäki, Jaana, \& Valtonen, Sanna (2012). Kelluva kiinnostavuus: Journalismin merkitys ihmisten sosiaalisissa verkostoissa. Tampere: Vastapaino.

Hermes, Joke (2009). Audience studies 2.0: On the theory, politics and method of qualitative audience research. Interactions: Studies in Communication Q Culture 1: 1, 111-127.

Hermida, Alfred; Fletcher, Fred; Korrell, Darryl \& Logan, Donna (2012). Share, like, recommend: Decoding the social media news consumer. Journalism Studies 13: 5-6, 815-824.

Huotilainen, Anna (2005). Dimensions of novelty: Social representations of new foods. Helsingin yliopisto: EKT series 1335, Sosiaalipsykologian laitos.

Höijer, Birgitta (2011). Social representations Theory. A new theory for media research. Nordicom, Review 32: 2, 3-16.

Jaspars, Jos M. F \& Fraser, Colin (1984). Attitudes and social representations. Teoksessa: Farr, Rob M. \& Moscovici, Serge (toim.). Social Representations. Cambridge: University Press.

Jenkins Henry; Ford, Sam \& Green, Joshua (2013). Spreadable Media: Creating Value and Meaning in a Networked Culture. New York and London: NYU Press.

Kilpiö, Anna (2008). Opettajien teknologiasuhteen luonne ja muodostuminen. Espoo: Otamedia.

Larsson, Anders Olof (2011). Interactive to me - interactive to you? A study of use and appreciation of interactivity on Swedish newspaper websites. New Media Q Society 13: 7, 1180-1197.

Lee, Chei Sian \& Ma, Long (2012). News sharing in social media: The effect of gratifications and prior experience. Computers in Human Behavior 28: 2, 331-339.

Lietsala, Katri \& Sirkkunen, Esa (2008). Social Media: Introduction to the Tools and Processes of Participatory Economy. Tampere: Tampere University Press.

Lim, Jeongsub (2014). Effects of social users' attitudes on their perceptions of the attributes of news agency content and their intentions to purchase digital subcriptions. New Media Q Society, 1-19.

Livingstone, Sonia (2004). The challenge of changing audiences: Or, what is the audience researcher to do in the age of the internet? European Journal of Communication, 19: 1, 75-86.

Livingstone, Sonia (2013). The participation paradigm in audience research. Communication Review, 16: $1-2,21-30$. 
Malmelin, Nando \& Villi, Mikko (2015). Audience community as a strategic resource in media work: Emerging practices. Journalism Practice, julkaistu ensiksi verkossa. Saatavilla: http://www.tandfonline.com/doi/abs/10. 1080/17512786.2015.1036903?journalCode=rjop2O\#.Vc2_Lni5M7Y.

Matikainen, Janne \& Villi, Mikko (2013). Mobiilit mediasisällöt: Sisältöjen tuottaminen, jakelu ja kulutus sosiaalisessa mediassa. Viestinnän tutkimuskeskus CRC, Sosiaalitieteiden laitos, Helsingin yliopisto.

Matikainen, Janne \& Villi, Mikko (2015). Yleisö ja yhteisöt mediassa. Teoksessa: Malmelin, Nando \& Villi, Mikko (toim.). Mediajohtaminen: näkökulmia uudistuvaan media-alaan. Helsinki: Gaudeamus, 77-94.

McGuire, William J. (1985). Attitudes and attitude change. Teoksessa: Lindzey, Gerdner \& Aronson, Elliot (toim.). Handbook of Social Psychology. Volume II. New York: Random House.

Merrin, William (2009). Media Studies 2.0: Upgrading and open-sourcing the discipline. Interactions: Studies in Communication and Culture 1: 1, 17-34.

Miegel, Fredrik \& Olsson, Tobias (2012). A generational thing? The internet and the new forms of social intercourse. Journal of Media Q Cultural Studies 26: 3, 487-499.

Moscovici, Serge (1984). The phenomenon of social representations. Teoksessa: Farr, Rob M. \& Moscovici, Serge (toim.). Social representations. Cambridge: University Press.

Mørk Petersen, Søren (2008). Loser generated content: From participation to exploitation. First Monday 13: 3.

Napoli, Philip M. (2009). Navigating producer-consumer convergence: Media policy priorities in the era of usergenerated and user-distributed content. McGannon Center Research Resources. Paper 6.

Newman, Nick \& Levy, David A. L. (2013). Reuters Institute Digital News Report 2013: Tracking the Future of News. Reuters Institute for the Study of Journalism, University of Oxford.

Newman, Nick \& Levy, David A. L. (2014). Reuters Institute Digital News Report 2014: Tracking the Future of News. Reuters Insititute for the Study of Journalism, University of Oxford.

OECD (2007). Participative Web and User-Created Content. OECD Publishing.

Potter, Jonathan (1996). Attitudes, social representations and discursive psychology. Teoksessa: Wetherell, Margaret (toim.). Identities, Groups and Social Issues. London: Sage \& The Open University.

Potts, Jason; Hartley, John; Banks, John; Burgess, Jean; Cobcroft, Rachel; Cunningham, Stuat \& Montgomery, Lucy (2008). Consumer co-creation and situated creativity. Industry Q Innovation 15: 5, 459-474.

Rainio, Kullervo \& Helkama, Klaus (1974). Sosiaalipsykologian oppikirja. Helsinki: WSOY.

Ritzer, George \& Jurgenson, Nathan (2010). Production, consumption, prosumption: The nature of capitalism in the age of the digital "prosumer". Journal of Consumer Culture 10: 1, 13-36.

Räty, Hannu (1987). Uhka vai uhri: tutkimus mielisairauteen asennoitumisesta. Joensuun yliopiston yhteiskuntatieteellisiä julkaisuja n:o 10.

Sakki, Inari \& Menard, Rusten (2014). Ankkurointi, naturalisointi ja muutos sosiaalisten representaatioiden tutkimuksessa. Teoksessa: Myyry, Liisa; Ahola, Salla; Ahokas, Marja \& Sakki, Inari (toim.). Arkiajattelu, tieto ja oikeudenmukaisuus. Sosiaalitieteiden laitos, Helsingin yliopisto.

Schäfer, Mirko T. (2011). Bastard Culture! How User Participation Transforms Cultural Production. Amsterdam: Amsterdam University Press.

Tilastokeskus (2014). Väestön tieto- ja viestintätekniikan käyttö 2014. Helsinki: Tilastokeskus.

Vesala, Kari Mikko \& Rantanen, Teemu (1999). Pelkkä puhe ei riitä. Maanviljelijän yrittäjäidentiteetin rakentumisen sosiaalipsykologisia ehtoja. Helsinki: Yliopistopaino.

Villi, Mikko (2011). Sosiaalinen kuratointi verkossa: Mediasisältöjen sosiaalinen kulutus ja osallistava yleisöys. Media Q viestintä 34: 4, 48-65.

Villi, Mikko (2012a). Käyttäjien käyttäjät: Mediayhtiöt ja käyttäjien implisiittinen osallistuminen sosiaalisessa mediassa. Lähikuva 25: 2, 9-21.

Villi, Mikko (2012b). Social Curation in Audience Communities: UDC (user-distributed content) in the networked media ecosystem. Participations: The International Journal of Audience and Reception Studies 9: 2, 614-632.

Villi, Mikko (2014). Medialla töissä. Teoksessa: Lehtonen, Mikko; Valaskivi, Katja \& Kuusela, Hanna (toim.). Tehtävä kulttuurille: Talouden ja kulttuurin muuttuvat suhteet. Vastapaino: Tampere, 326-343.

Väliverronen, Esa (toim.) (2009). Journalismi murroksessa. Helsinki: Gaudeamus.

Westlund, Oscar (2010). New(s) functions for the mobile: A cross-cultural study. New Media Q Society 12: 1, 91-108. Westlund, Oscar \& Bjur, Jakob (2014). Media life of the young. Young 22: 1, 21-41.

Zanna, Mark P. \& Rempel, John K. (1988). Attitudes: A new look at an old concept. Teoksessa: Bar-Tal, Daniel \& Kruglanski, Arie W. (toim.). The Social Psychology of Knowledge. Cambridge: Cambridge University Press.

Östman, Johan (2012). Information, expression, participation: How involvement in user-generated content relates to democratic engagement among young people. New Media Q Society 14: 6, 1004-1021. 